FACULdAde de FormaÇão de PROFESSORES

\title{
CAMPO LEXICAL E NEOLOGIA: CRIATIVIDADE LINGUÍSTICA EM FAVOR DA ARGUMENTAÇÃO
}

\author{
Anderson de Souto (UERJ) \\ otuos@hotmail.com
}

\section{Introdução}

Este trabalho tem por objetivo refletir sobre a exploração do campo lexical e da criação neológica como estratégia argumentativa na construção de um artigo de opinião, de André Petry, publicado em agosto de 2007 na revista Veja.

Privilegio, para esse fim, aspectos importantes sobre o fenômeno da neologia, considerando-o como manifestação da criatividade linguística presente em discursos diversos. Além disso, considero seu uso intencional, associado à exploração do campo lexical, como recurso estratégico para construir argumentação.

Por fim, apresento a validade da abordagem do texto nas aulas de língua portuguesa, revendo o trabalho com o texto argumentativo. Assim, as noções de autor e de leitor "estrategistas" são fundamentais, pois trazem uma postura que considera a criatividade e a argumentatividade como peças importantes para o desenvolvimento da competência linguística (de modo amplo) e da competência lexical (de modo específico) dos estudantes.

\section{Competência e criatividade linguística: a presença da neologia nos diversos discursos}

O linguista romeno Eugenio Coseriu, em favor da mediação entre os conhecimentos linguístico-discursivos e a prática da educação linguística, traz um grande auxílio ao redimensionamento desta. Ele discute, em Competência Lingüística: elementos de la teoria del hablar (1992), o que considera pertinente ao saber linguístico prático 
(geral) dos falantes. Falo dos três níveis que compõem a competência linguística ${ }^{1}$ e que estão presentes em cada ato discursivo:

- no nível universal, está o saber elocucional, que é o conhecimento de mundo do falante, evidenciado naquilo que é possível ser dito em qualquer língua, a que se atribui o juízo da congruência;

- no nível histórico, está o saber idiomático, que é o saber falar uma determinada língua, seguindo as regras intrínsecas a suas construções, compondo a dimensão morfossintática e lexicossemântica, a que se atribui o juízo da correção;

- no nível individual, está o saber expressivo, que é o saber estruturar e compreender textos diversos nas modalidades escrita e falada, bem como, através deles, se comportar socialmente, nas mais diversas situações de interação comunicativa, a que se atribui o juízo da adequação.

No bojo dessa competência (saber complexo que se desenvolve em três níveis), em relação aos saberes idiomático e expressivo, está o que se considera nos estudos linguísticos como competência lexical.

A competência lexical permite ao falante compreender a significação das palavras de uma língua, seus processos morfossintáticos e semânticos de criação, assim como seu intercâmbio com outros itens léxicos, o reconhecimento de novas formas e seu uso intencional (FERRAZ, 2008). Ela desenvolve-se ao longo das interações comunicativas do falante. Essa competência evidencia uma das propriedades intrínsecas à linguagem: a criatividade.

Para Coseriu (1987), a criatividade é algo que faz parte da essência da linguagem. Argumenta o autor que é ela própria (a linguagem) atividade criativa humana, identificando-a com a poesia, por meio da etimologia do termo grego poiesis: criação.

Assim, é através dela que o homem apreende o mundo e o manifesta, dando existência discursiva aos objetos do real, ordenando-os (COSERIU, 1987). Desse modo, a criatividade estará presente em qualquer manifestação linguística humana.

${ }^{1}$ Para Coseriu (1992), a competência linguística constitui um saber intuitivo ou técnico dependente da cultura, que se desenvolve nos três planos do falar em geral, e é mobilizado para a construção de discursos sempre novos em situações concretas de interação verbal. 
O léxico, o inventário aberto de palavras da língua de uma determinada comunidade, que reflete as diversas experiências tradicionais de uma comunidade linguística (FERRAZ, 2008), é um grande campo para o exercício dessa criatividade.

Em relação à criação linguística no nível do léxico, há no uso estético da linguagem literária inúmeros exemplos, haja vista criações realizadas por Guimarães Rosa e por Drummond, dois de nossos maiores escritores. Esses autores exploram constantemente o léxico, desviando normas linguísticas, de acordo com as diversas possibilidades do sistema, de modo expressivo e inovador.

É inegável que na literatura surgem muitas criações linguísticas e que o uso criativo do léxico constitui-se um de seus maiores exemplos. Porém, a exploração das potencialidades lexicais não serve somente à literatura, e seu uso expressivo não está presente apenas no universo artístico, conforme argumenta Coseriu (1987).

Ela serve comumente ao enriquecimento do inventário vocabular da língua, configurando um dos aspectos de seu processo dinâmico ${ }^{2}$, com palavras formadas para suprir necessidades surgidas nas mudanças sociais.

Além disso, a criatividade não se configura apenas na introdução de formas sempre novas e originais ${ }^{3}$. Se assim o fosse, a linguagem se tornaria um amontoado de formas heterogêneas, perdendo sua dimensão histórica, deixando de servir à comunidade de falantes como manifestação da intersubjetividade.

Há constantemente, na sociedade, exigência de novos termos e significados para se referir a fenômenos, objetos, processos que surgem ao longo do tempo. A língua, em sua função social, acompanha essas exigências, haja vista termos da linguagem técnico-cien-

\footnotetext{
${ }^{2}$ Coseriu (1979) expõe que "a própria funcionalidade atual implica uma superação possível do 'atual estado de língua' para o futuro [...] para os próprios falantes a língua atual não é apenas conjunto de formas já realizadas, modelos atualizáveis, mas também é técnica para ultrapassar 0 realizado, 'sistema de possibilidades' (sistema)" (p. 231).

3 Sobre o papel da criatividade, explica Carlos Franchi (2006, p. 100) que "é preciso, porém, ampliar a concepção de criatividade. Ela não pode limitar-se ao comportamento original, à inspiração e ao desvio [...] mas também se cria quando se seguem as regras históricas e sociais como as regras da linguagem".
} 
tífica cunhados a cada nova descoberta. Não se pode negar, entretanto, que novos termos servem também a intencionalidades expressivas surgidas no cotidiano.

Esses processos de criação de novos vocábulos recebem o nome de neologia (ALVES, 2007) e o novo termo, resultado desse processo, neologismo. Essa palavra encontra seu étimo numa formação híbrida do latim (neo - novo) e do grego (logos - palavra), constituindo-se uma novidade linguística.

A linguagem corrente apresenta constantemente criações desse tipo, contribuindo para a renovação do acervo lexical (ALVES, 2007). Esses neologismos apresentam-se em diversas esferas sociais, como a jornalística, a política, a científica, a cotidiana etc. Sobre sua presença em diferentes linguagens, observa André Valente:

Gostaria de ressaltar que a literatura [...] sempre teve papel decisivo na criação de neologismos. Se Camões consolidou a língua portuguesa e Guimarães Rosa a reinventou, a criação neológica esteve presente neste percurso poético-linguístico. Atualmente, junto à literatura, é inegável que linguagens várias têm contribuído para a renovação do nosso léxico. (VALENTE, 1997, p. 98)

O autor deixa entrever em seu texto que a criação vocabular, embora sirva, e muito, ao uso estético da linguagem, não é terreno apenas deste. Muitas são as manifestações criativas presentes, com diversas finalidades, no cotidiano que figuram ao lado do literário.

A manifestação da produtividade lexical pode, em diversas linguagens, sobretudo no discurso jornalístico, ser associada à exploração dos campos lexicais. É importante, aqui, conceituar campo lexical e distingui-lo de campo semântico.

Câmara Jr. (1968) apresenta uma conceituação para os dois termos. Para o autor: o primeiro (campo lexical) refere-se à família léxica, palavras que têm em comum a mesma base significativa (raiz), que se multiplica através dos processos de formação de palavras; o segundo (campo semântico) refere-se à associação de significação para certo número de palavras de distintas bases, que se relacionam a um mesmo fenômeno, como por exemplo, palavras da área política (político, governo, partido etc.). 
A seguir, apresento uma análise detida de um artigo de opinião, no qual discuto o uso expressivo do neologismo e do campo lexical, cuja finalidade é ser uma estratégia ${ }^{4}$ que objetiva a defesa de um ponto de vista.

\section{Neologismo, campo lexical e construção da argumentação}

Em meados do ano de 2007, houve um gravíssimo acidente aéreo com um avião Airbus da TAM (voo no 3054) no aeroporto de Congonhas, em São Paulo, no qual morreram todos os passageiros, chocando a sociedade. Após, buscavam-se as causas do acidente, o que certamente afetaria seus responsáveis.

$\mathrm{O}$ acidente gerou diversos textos publicados em algumas edições da revista Veja, que anunciavam erro humano como causa do acidente. Porém, embora o piloto tivesse errado, outras causas poderiam ter contribuído para seu agravamento, como o fato de a pista de pouso e decolagem do aeroporto ser curta. Essas causas secundárias atribuiriam responsabilidades a políticos, inclusive ao ex-presidente, Luiz Inácio Lula da Silva, responsável pela obra de expansão do aeroporto em 2005.

Após o acidente, houve uma grande especulação política sobre o caso, que dividiu governo e oposição. Essa especulação é criticada por André Petry no seguinte artigo de opinião publicado em agosto de 2007:

\section{Dentro do politicovil}

André Petry

Tudo já indicava que estamos cada vez mais distantes da política e mais próximos da politicalha, mas a tragédia de Congonhas jogou uma luz intensa sobre essa deformação nacional. A politiquice pós-tragédia dividiu Brasília em dois bandos. Os politiqueiros do governo torcem para que a principal explicação do desastre seja um defeito no avião ou erro do piloto, aliviando a barra governista. Os politiqueiros da oposição fazem figa para que a pista de Congonhas seja a grande culpada, o que

\footnotetext{
4 Ingedore Koch (2006) defende que produtor e interpretador de textos são estrategistas, que mobilizam uma série de recursos, para atuarem linguisticamente na construção de sentidos. Esse agir pressupõe intencionalidade por parte do produtor, constituindo, assim, seu projeto de dizer.
} 


\section{DEPARTAMENTO DE LETRAS}

compromete o governo. Como as investigações iniciais sugerem que o problema principal ocorreu na cabine do avião, e não na pista do aeroporto, politiquinhos governistas talvez se sintam autorizados a voltar a brincar de top, top, top.

Essa versão amesquinhada da política não é exclusividade brasileira, mas nas democracias mais maduras os politicastros ao menos se empenham em esconder seus impulsos. Aqui, as coisas estão mais debochadas. É impressionante a incapacidade dos nossos politicantes de fazer a política grande, nobre, a política que, apesar de todas as divergências, leva em conta que, afinal, vivemos todos juntos. Mas nossos politicóides são indiferentes a esse projeto de bem comum. Vulgarizaram-se tanto que se apartaram do sentimento do brasileiro médio, que se espantou de verdade, se chocou de verdade com o avião explodindo, se solidarizou de verdade com o drama das famílias. O senhor Marco Aurélio "Top, Top, Top" Garcia é exemplo dessa alienação. Filmado, como ele diz, de "forma clandestina", Garcia mostrou preocupar-se menos com a comoção nacional e mais com o impacto eleitoral da tragédia. Coisa de politiquilho.

Com o mesmo alheamento, o presidente Lula sumiu por três dias depois do maior acidente aéreo do país, tal como fazem os oposicionistas na hora em que são postos à prova. José Serra desapareceu quando o PCC colocou São Paulo de joelhos. Agora, como Congonhas não é obra sua, Serra aparece em Congonhas. E Lula, como Congonhas é obra sua, some de Congonhas, some de Porto Alegre e cancela visitas a toda a Região Sul do país, exatamente para onde deveria viajar se vencesse a covardia da politicagem, se deixasse de fazer politicócoras.

Com politicalhões assim, corremos o risco de ficar numa situação algo parecida com a condição a que o nazismo relegou suas vítimas, conforme a formulação de Hannah Arendt: não eram consideradas seres humanos, apenas futuros cadáveres.

Basta de politicoveiros. Precisamos de políticos.

(Veja. 1/8/2007. http://veja.abril.com.br/010807/andre_petry.shtml. Acesso em: set. de 2010)

O artigo de opinião é um gênero 5 que se organiza no tipo textual argumentativo, que se justifica por ser uma ação verbal segundo a qual se pretende defender uma tese sobre acontecimentos polêmicos atuais. É escrito geralmente por uma autoridade que possui noto-

\footnotetext{
${ }^{5}$ Marcuschi (2005) conceitualiza o termo gênero como um evento textual flexível, dinâmico e um fenômeno histórico que surge das necessidades e das atividades socioculturais; por isso, está arraigado à vida cultural e social do homem, de modo a atrelar-se a seus eventos sociocomunicativos, que, por serem diversos, manifestam diversidade dos gêneros.
} 
riedade no assunto e dirige-se a um público leitor considerado, potencialmente, envolvido no debate.

André Petry escolhe tal gênero (anunciando já nesta escolha seu projeto de dizer), parar compartilhar com os leitores sua opinião sobre a atitude de políticos brasileiros que tentam fazer de uma tragédia chocante para a população, um caso eleitoreiro.

Apresenta-se, pois, contrário a essa postura, na tentativa de convencer os leitores de que, para uns (os governistas), a tragédia mancharia suas reputações junto ao grande público (eleitores) e de que, para outros (os oposicionistas), ela poderia ser uma via de acesso a críticas, fazendo aqueles (os governistas) perderem votos na eleição vindoura à época.

Tese lançada, para concretizar seu propósito de dizer, o autor lança mão de alguns procedimentos argumentativos ${ }^{6}$ instados na macroestrutura do texto ${ }^{7}$, para desenvolvê-lo de modo a conduzir o leitor à conclusão: exemplifica a "deformação nacional" de nossa política com atitudes de políticos governistas e oposicionistas em relação ao acidente de Congonhas; compara "essa versão amesquinhada da política" com a de outras democracias; exemplifica o interesse pessoal com o caso de Marco Aurélio Garcia; exemplifica "o alheamento político" com as atitudes de Lula e Serra; compara a atitude dos nossos políticos, no pós-tragédia, a dos nazistas no holocausto.

Ao lado desses recursos argumentativos mais amplos, ele manuseia, por conseguinte, instâncias gramaticais ${ }^{8}$, postas no nível microargumentativo como "pistas" para defender sua tese. Suas opções baseiam-se na construção do campo lexical da política.

$\mathrm{O}$ autor, então, explora a produtividade léxica de modo expressivo e intencional. Usa, para tanto, de variados termos já dicio-

\footnotetext{
${ }^{6}$ Procedimentos argumentativos, para Citelli (1994), são mecanismos, estratégias, recursos comuns à modalidade de convencimento e persuasão.

${ }^{7}$ Organização do todo do texto.

8 Para Citelli (1994), as instâncias gramaticais são outros recursos para construir argumentação. Compõem usos léxicos e gramaticais, como: escolhas vocabulares, expressões de valor fixo, figuras de linguagem, estruturas sintáticas etc. Dentre elas, elenco o neologismo e 0 campo lexical.
} 
narizados ${ }^{9}$, todos de sentido pejorativo, para caracterizar a imagem dos políticos, que julga afastarem-se da política "grande" e "nobre".

O vocábulo primitivo política é, então, empregado, no texto, em seu sentido positivo (ação de governar para promover o bem comum, o bem estar do Estado), em oposição a seus derivados já existentes na língua, todos de sentido negativo, enfatizando, assim, as ações dos políticos frente ao acidente com o voo 3054:

- politicalha - substantivo feminino formado de político + alha, usado, com intenção pejorativa (como em gentalha), para indicar o grupo de maus políticos que se dedicam a interesses pessoais, em detrimento do bem do povo.

- politiquice - substantivo feminino formado de política + -ice (sufixo de valor pejorativo, presente em chatice, canalhice etc) que se refere às ações dos políticos no pós-tragédia, consideradas pelo autor como sujas, mesquinhas, vergonhosas, uma "deformação nacional", indiferentes a uma catástrofe que chocou todo o país.

- politiqueiros - adjetivo substantivado formado de político + -eiro, referente aos políticos governistas e oposicionistas praticantes da "má" política, que não escondiam suas ações negativas nem com elas se constrangiam.

- politicastros - substantivo masculino, formado de político + -astro (aquele que faz as vezes de), referente aos políticos das democracias mais maduras, que, ao menos, escondem suas ações negativas, sendo menos explícitos. Os politicastros são aqueles parecem políticos, no sentido positivo do termo, são aqueles que estão na posição de políticos, mas não praticam a política "nobre".

- politicantes - substantivo masculino formado de político + -ante (aquele que pratica), referente aos políticos brasileiros em geral, praticantes das políticas partidárias ou das "políticas pessoais".

- politicoides - adjetivo substantivado composto por político + -oide (valor pejorativo presente em palavras como intelectualoide - falso intelectual), que se refere também aos políticos brasileiros, considerados pseudopolíticos, de pouco valor.

- politiquilho - substantivo composto por político + -ilho (sufixo de valor diminutivo ou pejorativo), referente a Marco Aurélio Garcia, exemplo da política negativa, que, filmado, "mostrou preocupar-se menos com a comoção nacional e mais com o impacto eleitoral da tragédia".

${ }_{9}^{9}$ Presentes no Grande dicionário etimológico-prosódico da língua portuguesa, de Silveira Bueno, da Editora Saraiva, publicado em Portugal, em 1968. 


\section{FACULDADE de FoRMAÇÃO de PROFESSORES}

- politicagem - substantivo formado por política + -agem, referente à atitude política no mau sentido, a dos arranjos e conchavos, mais relacionada a interesses próprios, em detrimento dos interesses do povo.

- politicalhões - substantivo masculino composto por político + -alho + ão, que categoriza os figurões negativos da política, os maus políticos brasileiros, exemplificados no texto.

Além do uso estratégico-persuasivo do campo lexical, o autor explora também criações neológicas vocabulares a partir da palavra político. Esses neologismos contribuem para a construção da orientação argumentativa do texto ${ }^{10}$, contrária às atitudes dos políticos, sendo mais um recurso importante para sua argumentatividade ${ }^{11}$. Eles buscam atribuir aos políticos valor negativo, reafirmando a tese defendida:

- politicovil - neologismo criado por Petry, introduzido no título - Dentro do políticovil -, formado por processo de composição, em que se aglutinam as palavras político e covil, gerando uma nova significação, já que se associa o valor semântico do termo político ao sentido pejorativo contido em covil. O vocábulo designa, pois, antro, espaço ocupado por políticos malfeitores, corruptos.

- politiquinhos - neologismo criado a partir da junção da base político ao sufixo -inho, explorando a polissemia sufixal, conferindo novo matiz semântico a político, que adquire valor depreciativo. Os políticos do governo se amesquinham, tornando-se "politiquinhos".

- politicócoras - neologismo referente à atitude de Lula, que não apareceu em Congonhas após o acidente. Vocábulo formado por composição, unindo a palavra político à cócoras, que adquire sentido irônico, de tom provocativo, ressaltando a indignação do autor à atitude de Lula, considerando-o como alguém que ignora uma situação trágica ou que com ela pouco se preocupa, mostrando-se covarde, envergonhando a si próprio.

- politicoveiros - outro neologismo formado por composição em que se unem as palavras político e coveiro, cujo sentido, no texto, é do político que contribui para mortes ou que se isenta de qualquer atitude para evitálas, mostrando-se, apenas, como aquele que abre covas. Petry relaciona

\footnotetext{
${ }^{10}$ Oliveira (2008) explicita que a orientação argumentativa é a conclusão (tese) a que o produtor do texto quer fazer o leitor chegar, provando-a com argumentação coerente, segundo a qual pode haver escolhas linguísticas que ressaltem melhorativa ou pejorativamente os discursos.

11 Para Koch (2002), o discurso, ação verbal plena de intencionalidade, que tenta agir sobre 0 comportamento do interlocutor, buscando fazê-lo compartilhar uma opinião, é ato que possui argumentatividade, sob o qual subjaz uma ideologia, dentro de um contexto social e histórico.
} 
esses políticoveiros aos nazistas do holocausto, para quem seus próprios eleitores "não são considerados seres humanos", mas "apenas futuros cadáveres".

Essas estratégias estilístico-argumentativas, que conferem valor pejorativo ao comportamento dos políticos envolvidos no caso e aos políticos brasileiros em geral, são ratificadas, no texto, pelas escolhas lexicais do campo semântico da bandidagem, como a palavra bando, presente no primeiro parágrafo do texto.

Com isso, Petry, intencionalmente, constrói "pistas" discursivas, marcando-as no texto, para fundamentar seu ponto de vista, expressando sua indignação em relação à nossa política. Ele, portanto, mostra-se solidário "ao sentimento do brasileiro médio".

\section{Repercussões pedagógicas: considerações finais}

É comum, em contexto escolar, ao se abordar argumentação, ensinar aos estudantes, que um texto argumentativo exige, na sua macroestrutura, um modelo básico: a introdução com a explicitação da tese a ser defendida; o desenvolvimento com parágrafos que ampliam e defendem a tese com argumentos; e a conclusão com a finalização do texto com a retomada da tese.

Em relação ao desenvolvimento de tal tipo de texto, as práticas pedagógicas, atestadas inclusive por muitos livros didáticos, giram em torno de procedimentos "tradicionais" para a construção de parágrafos argumentativos. Geralmente, focam-se métodos de enumeração, exemplificação, comparação/contraste, definição, alusão histórica, causa e consequência, citação ou testemunho ${ }^{12}$ etc.

Essa postura restringe o trabalho com a argumentação na escola, fazendo surgir algumas visões que reduzem o fenômeno do argumentar: o texto argumentativo passa a ser o único dotado de argumentatividade; sua liberdade de organização se engessa em estruturas pré-definidas; os procedimentos para desenvolvê-lo não privilegiam usos intencionais dos recursos linguísticos; geralmente não se

12 Cereja e Magalhães (2005) veem tais aspectos como fundamentais no texto dissertativoargumentativo, sem privilegiar outros que certamente são bem presentes em diversos gêneros (editoriais, cartas de leitor etc.) organizados no modo argumentativo. 
define um gênero determinado para a produção, apenas se solicita um texto dissertativo-argumentativo etc.

No entanto, muitas são as estratégias possíveis para se construir efeitos argumentativos, e tais efeitos não são próprios apenas do texto dissertativo-argumentativo canônico ${ }^{13}$. Pode-se construí-los explorando diversos recursos verbais e não verbais: imagens, diagramação, aspectos gráficos, figuras de linguagem, recursos gramaticais etc.

O texto de Petry serve de mote às aulas de língua portuguesa, de modo a se desenvolver, a partir dele, um trabalho de leitura crítica, com vistas a perceber a exploração da diversidade de recursos linguísticos em favor da argumentação.

Isso permitirá aos estudantes conscientizarem-se de que fatos são sempre apresentados a partir de um modo de ver, e de que as escolhas lexicais são fruto de intenções carregadas de valor ideológico: falamos sempre de um lugar determinado, de um modo determinado, para cumprir funções determinadas. Todo texto (não apenas o argumentativo) possui, de modo subjacente, um "querer dizer", que deixa "marcas" linguísticas.

Ao participarem ativamente da compreensão do texto, atentando para a carga ideológica presente nas escolhas do autor, os estudantes compreenderão que os usos linguísticos são dotados de argumentatividade, chegando à conclusão de que ler e escrever são atividades que requerem mais do que compreender e organizar textos.

O uso estratégico dos neologismos e do campo lexical constitui-se, assim, um importante recurso para a compreensão e a produção de textos na escola. Porém, requer um redirecionamento da visão de língua em tal contexto.

A concepção de língua e de texto coerente com tal ensino é a dialógica, segundo a qual o texto é o lugar da interação entre os fa-

\footnotetext{
13 Ingedore (2002) explicita que 0 ato de argumentar, orientação discursiva para determinada conclusão, questiona a distinção entre dissertação (exposição de ideias de modo neutro) e argumentação (exposição de ideias com um determinado posicionamento), considerando que a simples opção por uma opinião posiciona o sujeito em relação a um fato. Assim, a narração e a descrição possuiriam também, numa gradação, argumentatividade.
} 
lantes e estes são sujeitos ativos no processo interacional linguageiro, isto é, são agentes sociais que, de modo dialógico, constroem sentido, de acordo com um agir estratégico (KOCH, 2010).

De um lado dessa interação, está o leitor que, mobilizará uma série de conhecimentos, atuando cooperativamente, na tentativa construir sentidos a partir das "pistas" verbais, materializadas no texto. Do outro, está o autor que atuará sobre os recursos linguísticos disponíveis, lançando mão de uma série de estratégias de organização textual, orientando o leitor por meio de "pistas", no intuito de concretizar seu propósito de dizer. Assim constrói-se a ideia de autores e leitores estrategistas (KOCH, 2006).

Com isso, ser estrategista é ser atuante no jogo da linguagem, na tentativa de alcançar seus objetivos comunicativos. Essa perspectiva perfaz um caminho que prevê uma indissociável relação entre leitura, gramática, léxico e produção de textos.

Abre-se, a partir dessa visão, espaço, nas aulas de língua, para ampliar a noção de argumentação e de estratégias para concretizá-la. É, nesse sentido, que a exploração dos campos lexicais e dos neologismos pode surgir como uma dessas estratégias, que visam ao desenvolvimento da competência lexical (em sentido restrito) e da competência linguística (em sentido amplo) dos estudantes, pois parte da exploração de recursos linguísticos com finalidade intencional e expressiva, mobilizando usos criativos.

\section{REFERÊNCIAS BIBLIOGRÁFICAS}

ALVES, Ieda Maria. Neologismo: criação lexical. 3. ed. São Paulo: Ática, 2007.

CÂMARA Jr, J. Mattoso. Dicionário de filologia e gramática. Rio de Janeiro: J. Ozon, 1968.

CEREJA, William Roberto; MAGALHÃES, Thereza Cochar Magalhães. Texto e interação: uma proposta de produção textual a partir de gêneros e projetos. São Paulo: Atual, 2005.

CITELLI, Adilson. O texto argumentativo. São Paulo: Scipione, 1994. 
COSERIU, Eugenio. Sincronia, diacronia e história: o problema da mudança linguística. Trad. Carlos Alberto da Fonseca e Mário Ferreira. São Paulo: Presença, 1979.

. O homem e sua linguagem. 2. ed. Trad. Carlos Alberto da Fonseca e Mário Ferreira. Rio de Janeiro: Presença, 1987.

FERRAZ, Aderlande Pereira. Os neologismos no desenvolvimento da competência lexical. In: HENRIQUES, Claudio Cezar; SIMÕES, Darcilia. Língua portuguesa, educação e mudança. Rio de Janeiro: Europa, 2008, p. 146-162.

FRANCHI, Carlos; NEGRÃO, Esmeralda Vailati; MÜLLER, Ana Lúcia. Mas o que é mesmo "Gramática"?. São Paulo: Parábola, 2006.

KOCH, Ingedore Villaça. Argumentação e linguagem. São Paulo: Cortez, 2002.

2006.

. Desvendando os segredos do texto. São Paulo: Cortez,

; ELIAS, Vanda Maria. Ler e escrever: estratégias de produção textual. São Paulo: Contexto, 2010.

MARCUSCHI, Luiz Antônio. Gêneros textuais: definição e funcionalidade. In: DIONISIO, Angela Paiva; MACHADO, Anna Rachel; BEZERRA, Maria Auxiliadora (Orgs.). Gêneros textuais e ensino. 4. ed. Rio de Janeiro: Lucerna, 2005, p. 19-36.

OLIVEIRA, Helênio Fonseca de. Conflito entre a natureza pejorativa e meliorativa das escolhas lexicais e a orientação argumentativa do texto. In: HENRIQUES, Claudio Cezar; SIMÕES, Darcilia. Língua portuguesa, educação e mudança. Rio de Janeiro: Europa, 2008, p. 116-122.

VALENTE, André. A criação vocabular: os neologismos. In: PEREIRA, Maria Teresa G. Lingua e linguagem em questão. Rio de Janeiro: Eduerj, 1997, p. 87-100. 